\title{
Cellular stress after transferring human cornea from in vivo to in vitro milieu: a metabolomic approach
}

\author{
Tomasz Kryczka ${ }^{1,2 *}$ \\ ${ }^{1}$ Department of Medical Biology, Medical University of Warsaw, Warsaw, Poland \\ ${ }^{2}$ Department of Experimental Pharmacology, Mossakowski Medical Research Centre, Polish Academy of Sciences, Warsaw, Poland
}

\begin{abstract}
The transfer of the human cornea from a donor to the artificial storage media is accompanied by the transient stress response of the cells reacting to the traumatic change of the environment. The aim of this study was to investigate cellular stress-mediated changes in the tissue at the metabolic level. Eight human corneas were obtained post-mortem from 58-67 year-old donors and stored in Eusol- $\mathrm{C}$ at $+4^{\circ} \mathrm{C}$ for 3 days. The daily changes in metabolic profiles of the samples were investigated with HR MAS $1 \mathrm{H}$ NMR spectroscopy.

24 metabolites were assigned in the corneas. The significant differences in metabolic profiles between the preserved and non-preserved tissues were observed for ATP, butyrate, formate, glutamate, methionine and phenylalanine. The transfer of the human cornea from its natural environment to the storage media causes the metabolic changes appearing during the first days of the preservation. A further research should explain if they are temporary or they could have an impact on the graft survival in recipients.
\end{abstract}

\section{Introduction}

The separation of human cells from their natural in vivo environment should be considered as a very significant trauma factor influencing their enzymatic systems or functionality and, if the cells are the part of the homogenous tissue, the functionality of such tissue. Such trauma or related stress factors may lead to a transient loss of the integrity of cellular membranes and some affected cells may activate an irreversible apoptosis procedure. In some severe situations the apoptosis is a common phenomenon among the affected cells leading to the death of the whole tissue [1-3]. To prevent such phenomena storage media were developed aiming to mimic the natural environment. These artificial media contained, depending on a type of preserved cells or tissues, necessary nutrients in the concentrations corresponding to the ones found in vivo and were complemented with the further storage conditions such as e.g. antibiotics or the temperature $[4,5]$.

Despite the fact that the artificial storage media have been known for decades, there are still ongoing studies aiming at improving their contents or developing new concepts of the storage of the corneas (see e.g. [6]). In addition, the very well established storage media are also the subjects of the investigation of their impact on biochemical properties of the grafts (see e.g. [7-9]). Other studies aim at establishing a link between the storage duration or the storage technique and the transplantation outcome [10]. All these studies are of great interest of ophthalmologists, especially those involved in cornea grafting. Nowadays clinicians possess a detailed knowledge about the morphology changes appearing in corneas during their preservation in the storage media and this knowledge is used for the evaluation of the graft prior to the transplantation procedure [11,12]. Unfortunately, it is still not very much known about the immediate biochemical changes that appear in the tissue during the first few days of the storage.

The aim of this study was to reveal the biochemical changes in human transplant tissue transferred from the natural environment to the artificial storage media. The cornea tissues obtained from healthy donors and NMR spectroscopy tool for the metabolomic analysis were applied for this purpose.

\section{Materials and methods}

The study adhered to the tenets of the Declaration of Helsinki and local regulations with regard to the human studies and the use of human tissues and organs, and has been filed with the Bioethics Committee of the Medical University of Warsaw which has acknowledged the protocol of the study and has raised no objection.

\section{Corneas}

Eight human corneas were obtained from ten 58-67 years old donors 4-8 hours post-mortem. No systemic or chronic disease, or recent medication was reported in donors. None of the donors were a heavy alcohol drinker, or infected with a hepatitis virus, or suffered from an autoimmune disease or cancer. After evaluation by slit lamp biomicroscopy of the cornea quality compliance with European Eye Bank Association criteria [11], corneal buttons of $10 \mathrm{~mm}$ diameter (calliper-measured) were excised free of sclera and limbal rim. Then, a quarter of cornea (pizza slice) was separated and immediately frozen at $-80^{\circ} \mathrm{C}$ until analyzed. These samples were considered control. The

Correspondence to: Tomasz Kryczka, MSc, MD, PhD, Department of Medical Biology, Medical University of Warsaw, Ul. Nowogrodzka 73, 02 018 Warszawa, Poland, Tel: +48 604315103; Fax: +48 226253223; E-mail: kryczka.tomasz@gmail.com

Key words: cellular stress, cornea biochemistry, cold storage, metabolomics, NMR spectroscopy

Received: June 01, 2015; Accepted: June 09, 2015; Published: June 12, 2015 
remaining tissue was placed in the Eusol-C (Alchimia s.r.l., Padova, Italy) storage medium at $+4^{\circ} \mathrm{C}$. Every day the quarter of the cornea was separated from the remaining tissue, rinsed with cold $\left(+4^{\circ} \mathrm{C}\right)$ sterile $0.9 \%(\mathrm{w} / \mathrm{v}) \mathrm{NaCl}$ solution and frozen at $-80^{\circ} \mathrm{C}$. The corneas were collected for 3 days.

The corneas used for this study were disqualified for transplantation due to some epithelial damage inflicted upon dissecting.

\section{High-resolution magic angle spinning proton NMR (HR MAS ${ }^{1}$ H NMR) spectroscopy}

HR MAS ${ }^{1} \mathrm{H}$ NMR spectroscopy data was acquired on a 14.1 T model Avance DRX600 Bruker spectrometer (Bruker BioSpin $\mathrm{GmbH}$, Rheinstetten, Germany) operating at $600.132 \mathrm{MHz}$. Just prior to the analysis, the frozen samples were cut into pieces and immersed in cold $\left(+4^{\circ} \mathrm{C}\right) 25 \mathrm{mM}$ solution of sodium $\left[2,2,3,3-\mathrm{d}_{4}\right] 3^{\prime}$ trimethylsilylpropionate in $\mathrm{D}_{2} \mathrm{O}$ in a $4 \mathrm{~mm}$ diameter ( $50 \mu \mathrm{l}$ capacity) zirconia rotor. The spectra were recorded at $+4^{\circ} \mathrm{C}$ using a $4 \mathrm{~mm}$ ${ }^{1} \mathrm{H} /{ }^{13} \mathrm{C}$ MAS probe. The samples were spun at $5000 \mathrm{~Hz}$ and the number of scans was 512. Water suppression was done employing a pre-saturation selective pulse. Exponential line broadening of $0.3 \mathrm{~Hz}$ was used. Carr-Purcell-Meiboom-Gill spectra analysis was performed using MestreNova v. 5.1.0 software (Mestrelab Research, Santiago de Compostela, Spain). Peak areas were measured using absolute integrals and were normalised by the wet weight of the measured samples (weight range of corneal samples; immediately frozen: 7.3-12.1 mg; stored for: 1 day: 7.1-12.2 mg, 2 days: 7.4-11.9 mg, 3 days: 7.3-12.0 mg) and assignment of the metabolites in the spectra were performed as described earlier [7-9].

\section{Statistical analysis}

Detection limits for the studied metabolites are relatively high (in $\mu \mathrm{M}$ range) in HR MAS ${ }^{1} \mathrm{H}$ NMR spectroscopy. The absence of any of these metabolites was unlikely, and using metabolite titers of " 0 " for those below the respective detection limit would distort the outcome of statistical analysis. Hence, such 'null' titers were omitted.

Metabolite content data were analyzed by repeated measures oneway ANOVA with time of cornea storage in medium as the repeated measure factor. Then pairwise comparisons for all metabolites were done with Bonferroni correction (program R, ver. 2.10)

\section{Results}

Among all 24 low molecular weight metabolites assigned in the HR MAS ${ }^{1} \mathrm{H}$ NMR spectra (for a representative spectrum see Figure 1) six compounds were shown to change their concentration levels during the 3-days storage. Glutamate and phenylalanine were below the detection limit in the samples kept in Eusol-C. The levels of ATP, formate and methionine in the samples kept in Eusol-C for 2-3 days were significantly lower than in the control. Butyrate was not detected in the control samples (Figure 2).

The endothelial cell density (ECD) measurements of all corneas involved in the study showed the values between $2450-2750$ cells $/ \mathrm{mm}^{2}$. No significant ECD differences between the groups of samples were revealed.

\section{Discussion}

HR MAS (High Resolution Magic Angle Spinning) ${ }^{1} \mathrm{H}$ NMR (Proton Nuclear Magnetic Resonance) spectroscopy method has one primary advantage as an analytic tool compared to other methods: it

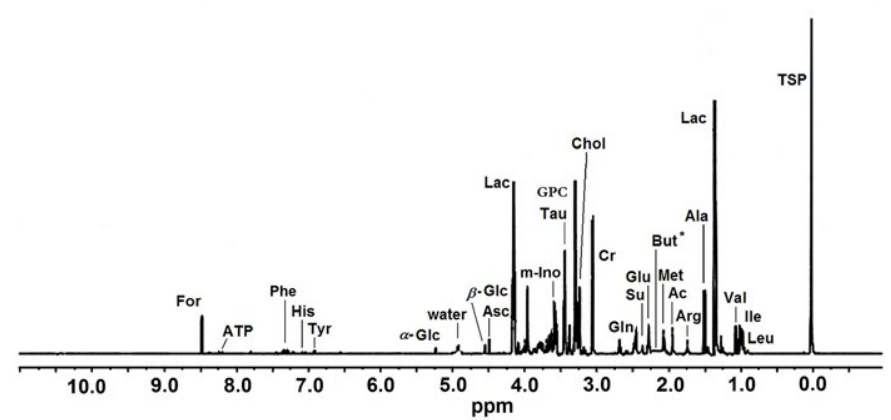

Figure 1. A representative HR MAS 1H NMR spectrum of intact human cornea sample. The ppm values were assigned using sodium [2,2,3,3-d4]3'-trimethylsilylpropionate (TSP) as the reference substance at 0 ppm. Ac, acetate; Ala, alanine; Arg, arginine; $A s c$, ascorbate; $A T P$, adenosine triphosphate; But, butyrate; Chol, choline; $\mathrm{Cr}$, creatine; For, formate; $\alpha$-Glc, $\alpha$-glucose; $\beta$-Glc, $\beta$-glucose; Gln, glutamine; Glu, glutamate; $G P C$, glycerophosphocholine; His, histidine; Ile, isoleucine; Lac, lactate; Leu, leucine; Met, methionine; m-Ino, myo-inositol; Phe, phenylalanine; Su, succinate; Tau, taurine; Tyr, tyrosine; $\mathrm{Val}$, valine. * Presumed location of But that was not detected in the control group corneas.
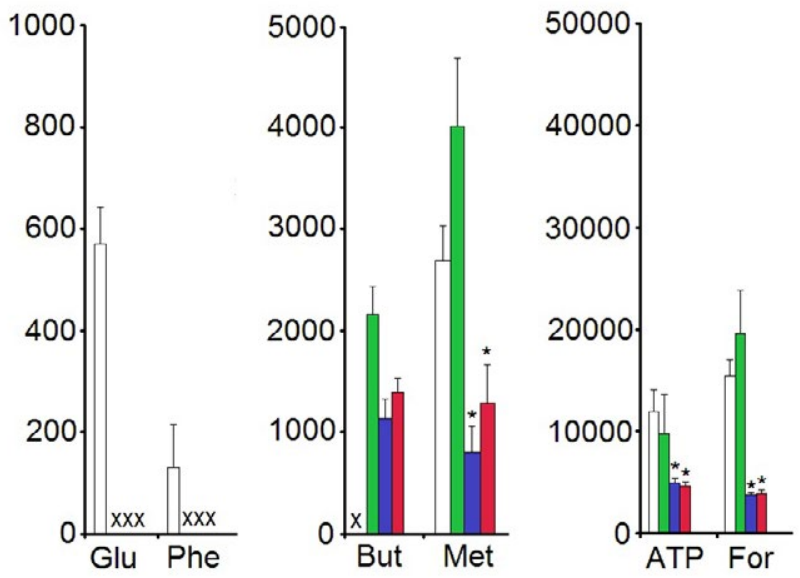

$\square$ control $\square$ day $1 \square$ day $2 \square$ day 3

Figure 2. The effect of time of storage on the contents of assigned low molecular weight metabolites. Data are means \pm SEM of HR MAS ${ }^{1} \mathrm{H}$ NMR peak integrals divided by tissue wet weight. *-p $<0.05 v s$. control; X-no detectable metabolite peak in the respective NMR spectra. For metabolite labels see legend for Figure 1.

allows to obtain large amounts of data from a single sample. However, it should be emphasized that the metabolite levels of compounds assigned in NMR spectroscopy reflect an averaged contents of the entire ('intact') tissue that is composed of several distinct cell types/layers. In addition, the compounds assigned in the ${ }^{1} \mathrm{H}$ spectra are limited to free, unbound, low molecular weight compounds. So, the method does not provide any information about 'the reserves' of the biochemical that could be chemically bound to bigger structures or molecules in the investigated tissue, but rather highlights the metabolic properties regarding the time-dependent changes of the concentrations of the assigned free compounds [13].

Transferring cells or tissues from a host environment to the storage systems has a great importance, e.g., in transplantation, especially in 
the situations when a grafted organ cannot be transferred directly from a donor to its recipient. The preservation of the in vivo properties of the organ in the in vitro conditions is, despite the immune characteristics, one of the most pivotal factors deciding about a success or a failure of grafting $[1,2]$. Some exception is the cornea transplantation, as the early outcomes of this procedure are usually excellent with a graft survival in about $90 \%$ of the cases in one year after the surgery [14]. This somehow results from the fact that cornea tissues are immune-privileged and the present-day surgery or eye banking procedures have significantly improved with years [15]. However, it should be emphasized that there are still some graft rejections reported of the unknown reasons, despite all the improvements mentioned above [14].

There are two main types of storage systems used for cornea banking: a warm and a hypothermic (cold) storage [16]. Under the hypothermic storage that was used in this study, the cornea is generally maintained in a commercially available medium at $2-8^{\circ} \mathrm{C}$, in the closed system from the preparation to the grafting. Low temperatures were supposed to minimize or even inhibit the cell metabolism and then, to reduce a cellular demand for metabolic energy and nutrients. In general, the aim of such approach was to preserve the original (in vivo) properties of the cornea [16]. However, the storage medium always represents a stressful environment for the donor tissue as no composition of the medium can replace the contents of the natural lachrymal fluid being the mixture of several compounds or secretions from glands located in the tissues circumventing the eye $[17,18]$.

Although the low temperature should minimize the cell metabolism, ATP levels were shown to decrease within the first days of the storage in Eusol-C (Figure 2). We have no explanation for such results except the suggestion that to protect the cells/tissue from the damage, the excess of ATP as an energy source, was displaced for maintaining the primary, at least, enzymatic systems protecting the cells. This consumption of ATP was not counterbalanced by its production, possibly due to the low temperature of the storage medium. The changes in ATP levels observed in this study confirmed the previous report by Redbrake et al. [19] showing a similar pattern of energy changes and increasing with time of the storage number of the damaged endothelial cells in the tissue. The thesis about the elevated protection-related consumption of ATP might be supported by the observed changes in the levels of the formate (Figure 2). This biochemical compound serves among others as an anti-oxidant protecting cells from oxidative damage [20]. Its deprivation in the tissue might suggest the increased exposition of cells to free radical species and indirectly - confirm the increased energy utilization.

Interestingly, methionine showed an identical pattern of concentration changes as ATP and the formate while glutamate and phenylalanine were decreased to even the undetectable concentration levels in the preserved samples (Figure 2). There are several possible explanations of such a phenomenon: e.g., an increased turnover or synthesis of the cellular proteins, a malfunction of some of the enzymatic systems in cells or a transient loss of the integrity of cellular membranes leading to the outflow of amino acids to the medium. The latter option should be particularly considered regarding the previous reports on the cornea cells death that increased during the cold storage [19,21-23]. In addition, the results of this study also support this mechanism of the deprivation of biochemical compounds in corneas. Free butyrate, a short chain fatty acid forming esters being the components of the cellular membranes and additional energy source [24], reached the detectable levels in the preserved cornea samples (Figure 2). On the other hand, Eusol-C - although a very basic medium - contains, among others, amino acids [25]. Then both, the release of metabolites from dying or dead cells to the adjacent tissue or into the storage medium as well as transporting chemical compounds from the storage medium to the tissue should also be considered.

The oxidative stress or any metabolic imbalances were never considered important in the qualification of the corneas for grafting. Much more attention was, and is still paid, to the immune factors, the presence of infectious pathogens and the cellular or structural integrity of the tissue and etc $[11,12]$. One should realize that the disintegration of the cells and tissue usually begins at the molecular level, when one metabolic compound exceeds the normal level or disappears from the cellular space leading to, for example, the malfunction of the individual, or many, metabolic pathway(s). If the disorder persists and no metabolic compensation mechanism is efficient enough to reverse the imbalance, the biochemical abnormalities accumulate till they reach the level of the irreversible changes that lead to the cell(s) death. The problem is that it is sometimes a long way from disturbing the metabolic pathways to the first symptoms of a cell death [26]. Possibly, the process that begins during the storage in an artificial medium might continue after the transplant procedure. Then, the recipient may face a sudden graft rejection that is clinically described as 'of the unknown reasons', which sometimes happens in the cornea transplantation [14]. A further research should explore this issue.

\section{Acknowledgment}

The author thanks Anna Midelfart and Jozef Langfort for their valuable advices, support and technical assistance.

\section{References}

1. Land WG (2012) Emerging role of innate immunity in organ transplantation: part I: evolution of innate immunity and oxidative allograft injury. Transplant Rev (Orlando) 26: 60-72. [Crossref]

2. Land WG (2012) Emerging role of innate immunity in organ transplantation part III the quest for transplant tolerance via prevention of oxidative allograft injury and its consequences. Transplant Rev (Orlando) 26: 88-102. [Crossref]

3. Calabrese EJ (2001) Apoptosis: biphasic dose responses. Crit Rev Toxicol 31: 607-13. [Crossref]

4. Jeng BH (2006) Preserving the cornea: corneal storage media. Curr Opin Ophthalmol 17: 332-7. [Crossref]

5. Bull AT (2010) The renaissance of continuous culture in the post-genomics age. $J$ Ind Microbiol Biotechnol 37: 993-1021. [Crossref]

6. Thanos S, Gatzioufas Z, Schallenberg M, König S, Meyer-Rüsenberg HW, et al. (2013) Clinical transplantation of individualized recipient serum-adapted cornea reduces the risk of graft rejection after keratoplasty. Cell Transplant 22: 477-91. [Crossref]

7. Kryczka T, Ehlers N, Nielsen K, Midelfart A (2012) Impact of organ culturing on metabolic profile of human corneas: preliminary results. Acta Ophthalmol 90: 761-7. [Crossref]

8. Kryczka T, Szaflik JP, Szaflik J, Midelfart A (2013) Influence of donor age, postmortem time and cold storage on metabolic profile of human cornea. Acta Ophthalmol 91: 83-7. [Crossref]

9. Kryczka T, Chrapusta SJ, Szaflik JP, Szaflik J, Midelfart A (2014) Impact of donor health on corneal biochemistry--an unexpected caveat from a pilot study. Ann Transplant 19: 129-37. [Crossref]

10. Heindl LM, Riss S, Adler W, Bucher F, Hos D, et al. (2013) Split cornea transplantation relationship between storage time of split donor tissue and outcome. Ophthalmology 120: 899-907. [Crossref]

11. EEBA Technical Guidelines Special Interest Group. Technical guidelines for ocular tissue.

12. The Eye Bank Association of America. Medical Standards (2003) Revision: D1.000 Donor Screening. 
13. Midelfart A (2009) Metabonomics-a new approach in ophthalmology. Acta Ophthalmol 87: 697-703. [Crossref]

14. Williams KA, Coster DJ (2007) The immunobiology of corneal transplantation. Transplantation 84: 806-13. [Crossref]

15. Panda A, Vanathi M, Kumar A, Dash Y, Priya S (2007) Corneal graft rejection. Surv Ophthalmol 52: 375-96. [Crossref]

16. Pels E, Beele H, Claerhout I (2008) Eye bank issues: II. Preservation techniques: warm versus cold storage. Int Ophthalmol 28: 155-63. [Crossref]

17. Cher I (2012) Fluids of the ocular surface: concepts, functions and physics. Clin Experiment Ophthalmol 40: 634-643. [Crossref]

18. Mantelli F, Argueso P (2008) Functions of ocular surface mucins in health and disease Curr Opin Allergy Clin Immunol 8: 477-483. [Crossref]

19. Redbrake C, Salla S, Frantz A, Reim M (1997) [Energy metabolism of the human cornea in various culture systems]. Klin Monbl Augenheilkd 210: 213-8. [Crossref]
20. Reda T, Plugge CM, Abram NJ, Hirst J (2008) Reversible interconversion of carbon dioxide and formate by an electroactive enzyme. Proc Natl Acad Sci U S A 105: 10654-8.

21. Komuro A, Hodge DO, Gores GJ, Bourne WM (1999) Cell death during corneal storage at $4^{\circ} \mathrm{C}$. Invest Ophthalmol Vis Sci 40: 2827-2832. [Crossref]

22. Jeng BH, Meisler DM, Hollyfield JG, Connor JT, Aulak KS, et al. (2002) Nitric oxide generated by corneas in corneal storage media. Cornea 21: 410-4. [Crossref]

23. Rauen U, Kerkweg U, Wusteman MC, de Groot H (2006) Cold-induced injury to porcine corneal endothelial cells and its mediation by chelatable iron: implications for corneal preservation. Cornea 25: 68-77. [Crossref]

24. Laeger T, Metges CC, Kuhla B (2010) Role of beta-hydroxybutyric acid in the centra regulation of energy balance. Appetite 54: 450-5. [Crossref]

25. Alchimia srl. Media for corneal storage at $+4^{\circ} \mathrm{C}$. Eusol-C

26. Halsted CH, Villanueva J, Chandler CJ, Stabler SP, Allen RH, et al. (1996) Ethanol feeding of micropigs alters methionine metabolism and increases hepatocellular apoptosis and proliferation. Hepatology 23: 497-505. [Crossref]

Copyright: $(2015$ Kryczka T. This is an open-access article distributed under the terms of the Creative Commons Attribution License, which permits unrestricted use, distribution, and reproduction in any medium, provided the original author and source are credited. 